\title{
PARTICIPATORY MARKET CHAIN APPROACH IN QUALITY FISH SEEDS DISSEMINATION PROCESS IN NEPAL
}

\author{
Shailesh Gurung $^{1 *}$, Vishwa C. Pokharel ${ }^{2}$ and Chandra Kanta Devkota ${ }^{2}$ \\ ${ }^{1}$ Tribhuvan University, Institute of Agriculture and Animal Science, Bhairahawa, Nepal \\ ${ }^{2}$ European Union, Agriculture and Nutrition Extension Project, CEAPRED, Nepal \\ *Corresponding Author Email: gurungshailesh@gmail.com
}

\begin{abstract}
Quality fish seeds production and dissemination is found quite lacking part in boosting up the production of aquaculture in Nepal since long decades. Commercialization in fish farming cannot jumped ahead in absence of available inputs and fish seeds are realized a great factor for subsistence to commercialization of fish farming activities. Participatory Market Chain Approach is found to be a key tool for the social and economic upliftment of farmers and different market actors in a common platform with a dynamic solution in a jointly supply chain modality. Limited and monopoly market of inputs supplier hinders the resilience of fishery sector both qualitatively and quantitatively in Nepal. It is extremely realized that the pocket level fish thematic group concept would be very fruitful in ensuring a milestone by representating village and cluster level problem solving arena among different actors, stakeholders and lead farmers for accession of quality inputs by mutual trust building environment covering wider area in a participatory way which will ensure supply chain of quality products, livelihood and income as well.
\end{abstract}

Keywords: Fish seed; Fish thematic group; Market actors; Service Provider; Value Chain; Participatory Market Chain Approach.

\section{Introduction}

Fishes are believed to be an auspicious and symbolize as symbol of fertility, strength and prosperity in Nepal. All the fisheries and aquaculture activities in Nepal are primarily governed by the policy laid down by the government (MoAC, 2009). Since decades, fisheries are believed with long-rooted tradition and custom in Nepalese society. Aquaculture is a relatively new and dynamic sector in Nepal in agricultural sector (APP, 1995).

The access of quality fish seed is found to be a prime constraint to the farmers in Nepal. Limited numbers of hatcheries and nurseries are unable to produce and meet the demand of fish seeds to the farmers. There is a high monopoly and syndicate tradition in fish seeds in Nepal. There is a bitter truth of no any strong legislation and control mechanism in ensuring the quality of fish seeds from the side of the government upto now. Fisheries association, producers, actors and civil societies are far behind in delivering their voice against adulteration of uncertified and qualityless fish seeds. They do not have fish seeds in time as per their requirement. Moreover, farmers are always deceived with poor growth performance of deteriorating fish seed quality. Farmers are unaware of standard size and weight of fish seeds, lack of proper information and technical knowhow, unknown market demand and unaccess to the government and other extension offices are the factors of backwardness of fish seeds production and distribution in Nepal. Different experiences have shown that fisheries and aquaculture development has a significant impact on communities in terms of relatively high returns on investments compared to other agriculture sub-sectors (Mathema, 1992; FPP, 2000). Government of Nepal has recognized immensely the contribution of aquaculture in poverty reduction, food and nutritional security, thus special attention has be paid enhancing production and productivity (MoAC, 2009; NARC, 2010). Based on the current national plan, fisheries have been focused as a tool for mainstreaming deprived, marginalized and poor communities in the society of the country (NARC, 2009; NARC, 2010). The specific attention has paid on livelihood improvement and poverty alleviation for economic growth through active participation of deprived and poor communities. Because of the significant physical distance between hatchery and nursery, the fish seeds reach to the farmers in poor condition 
and supply is often unable to keep pace with demand, especially in the case of large size fingerlings (Fact Sheet DSP, 2011).

Value chain development (VCD) in agriculture sector features basically in development programming aiming at stimulating economic growth and increasing the competitiveness of the agricultural sector (Humphrey and Navas-Alemán 2010; Staritz 2012; Stoian et al. 2012). The VCD approach challenges the government and civil society to look beyond individual actors, such as smallholders, cooperatives and market actors for achieving development goals. By focusing on the value chain and the links between the actors spread along it and development interventions can better identify common problems among actors in the chain and solutions that generate win-win outcomes.

\section{Materials and Methods}

Based on the easy access to the quality fish seeds, the ANEP project believes to establish numbers of fish seed outlets by which farmers can easily access to quality fish seeds (fingerlings) for a good production. For this initiative, project insisted on establishment of fish nursery in each pocket area, representating 4-5 VDCs by which farmers can achieve quality fingerlings in time. In this campaign, farmers were provided different kinds of messages, trainings and posters based on quality fish seeds in each working fish groups of the project led VDCs. During this course, fish thematic groups were formed under the umbrella of Participatory Market Chain Approach (PMCA) representating leader farmers from each group, fish hatchery, fish nursery, netting team member, retailer, agrovet owner, aqua medicine supplier and other input supplier. Based on the fish thematic group, monthly or demand based meeting and interaction program was organized in different issues and topics regarding availability of quality fingerlings, demand of fish, size of fingerlings, date of submission, responsible person, aqua medicines, different inputs including business plan preparation. Under thematic group members, a participatory approach with discussion on issues and problem solving and trusting building among the farmers and fish actors helps tremendously not only promotion of sale of fish seeds of the nursery and hatchery but also ensure the quality products offered by the actors to the farmers. It builds and ties up a mutual relationship among them with prosperous understanding with better result. By this approach, supply chain with participatory consensus and trust building strengthen among the different stakeholders binding in aquaculture production and development.

It was carried out based on target farmers group discussion, respondents, fish beneficiaries, input suppliers, fish nursery operators, hatchery owners, district level fisheries and agriculture development agencies. Furthermore, datas were computed by Microsoft Excel.

\section{Result and Discussion}

Agriculture and Nutrition Extension project of European Union, has been working in different sub-sector of agriculture since April 2012. There were seven collaborates namely IDE, WorldFish, CIMMYT, Save the children, CEAPRED, IRRI and BES. In ANEP, Aquaculture subsector was headed by WorldFish and implemented by CEAPRED in Nepal. ANEP had covered southern plain belt of Nepal consisting two districts, Rupandehi and Nawalparasi (Fig.1). ANEP had covered altogether 603 fish farmers of both districts of Nepal. The main objective of the project was improvement of livelihood, food security and market access. The aquaculture sub-sector was divided in three pocket within the two districts based on the area coverage, number of beneficiaries, number of fish group, etc (ANEP, 2013). It had altogether 41 groups in both project sites representing 20 groups in Rupandehi and 21 groups in Nawalparasi district. ANEP covered different ethnicities allocating 6\% Dalit, 47\% Janjati, 35\%, Madhesi and $12 \%$ others (Fig. 2). The overall gender percentage of ANEP beneficiaries was found $55 \%$ and $45 \%$ male and female in both districts, respectively (Fig. 3).

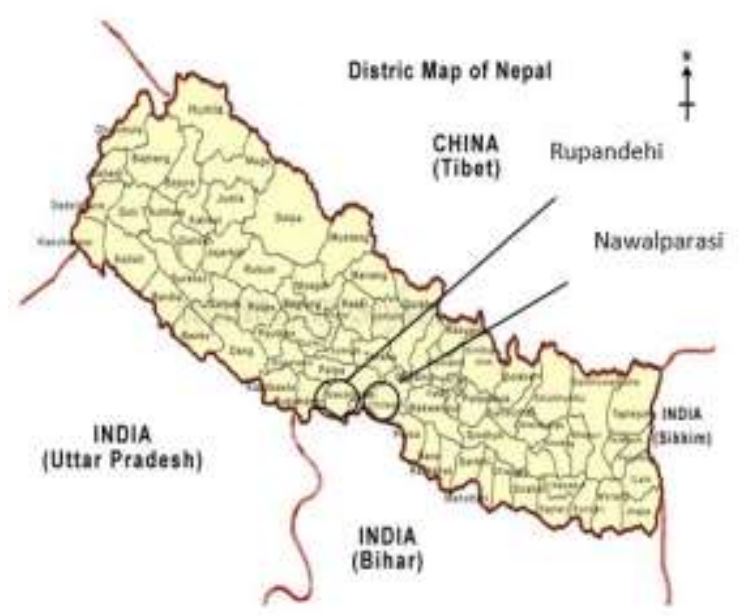

Fig. 1: ANEP working districts of Nepal

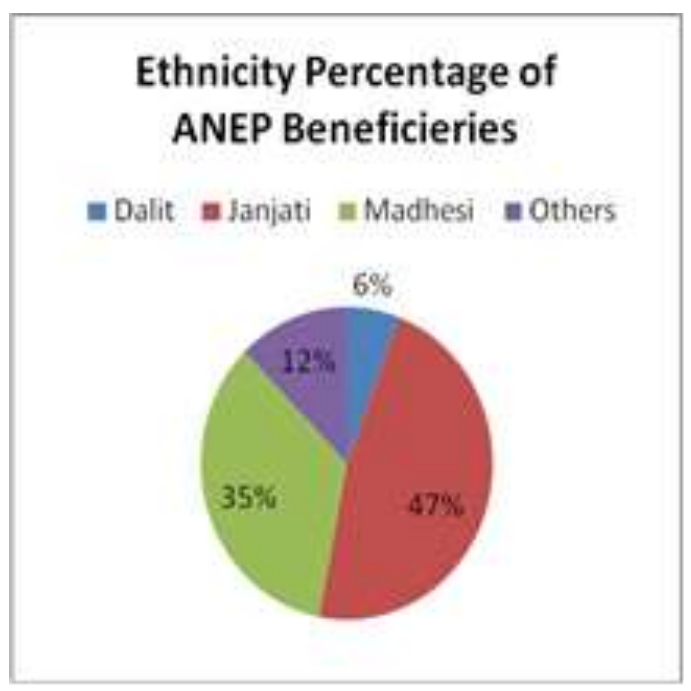

Fig. 2: Ethnicity Percentage of ANEP Beneficiaries 


\section{Gender Percentage of ANEP Beneficieries}

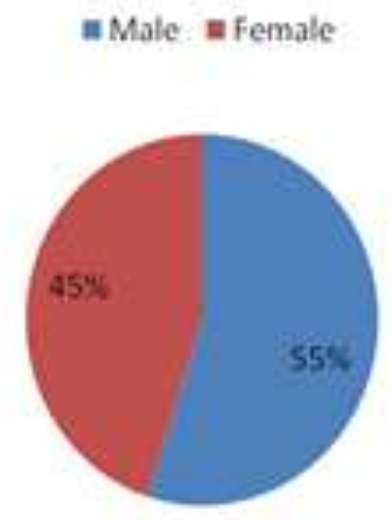

Fig. 3: Gender Percentage of ANEP Beneficiaries

Fish seed is the ultimate and inevitable part of aquaculture development. Although quality fish seed plays prime role in increasing fish production, most Nepalese farmers are deprived of accessing quality fish seeds for better output. Furthermore, establishment of fish nursery for rearing fry and fingerlings with good size is less practiced. If pocket wise or cluster wise approach of establishment of fish nursery would be developed in each pocket, then it will reduce the pressure of fish seed demand. And monopoly of hatcherer and nurserer will be reduced simultaneously.

Government of Nepal has a tremendous future plan in fish seed production scenario. Total Fish seed requirement by 2031/32 in Nepal is estimated 37, 81 00,000. It is classified based on the species following Carps 29,61,00,000, Tilapia 3,600,000, Cat fish (Pungus/ clarias) 3,600,000 and Trout 1,000,000 (Mishra, 2013). Since decades, farmers could not uplifted aquaculture productivity in absence of quality fish seeds in Nepal. Being very fertile resources of aquaculture, the linkage and coordination was not felt in a systematic way for the promotion of aquaculture in these districts. After the intervention, farmers were more united through the establishment of groups constructed by ANEP. Their capability strengthened through continuous training, interaction, on-farm and off-farm visits, supply chain development, PMCA, etc. During that three years period, they had been mobilized, empowered, enabled and internalize management of the resources properly. It was the ultimate outcome through participatory approach in decision making process directed by ANEP. By the intervention of ANEP, farmers were aware of construction of small nursery pond with grow-out pond that will ultimately assist in boosting up the good harvest. ANEP had able to succeed in disseminating knowledge about the establishment of nursery at least among the farmers' group and community as well.

The fish seed distribution system in Nepal, especially carps is presented in Figure 4. In the existing carp seed production and dissemination system seemed to be centralized within the reach of certain dealers and farmers who has good linkage with nurseries and hatcheries. This figure cannot justify the proper decentralization of the service to the pro poor farmers' accession. It reveals that only elites and big farmers can find the benefit. Furthermore, it is not clearly outlined the supply chain of inputs at lower level of the community i.e. village level at present formed by ANEP led fish nurseries was found to be a pretty and fertile entrepreneurship for small-scale farmers. It had good return, cut-off unemployment problems, fascinating job for even resource poor farmers. Many farmers had felt to establish nursery as a new opportunity for them. It reflected that quality fish seeds dissemination process led by ANEP intervention has not only benefitted to the core $\mathrm{HH}$ of the project but it has also assisted in outreach service by providing quality fingerlings to the non- project $\mathrm{HHs}$ too.

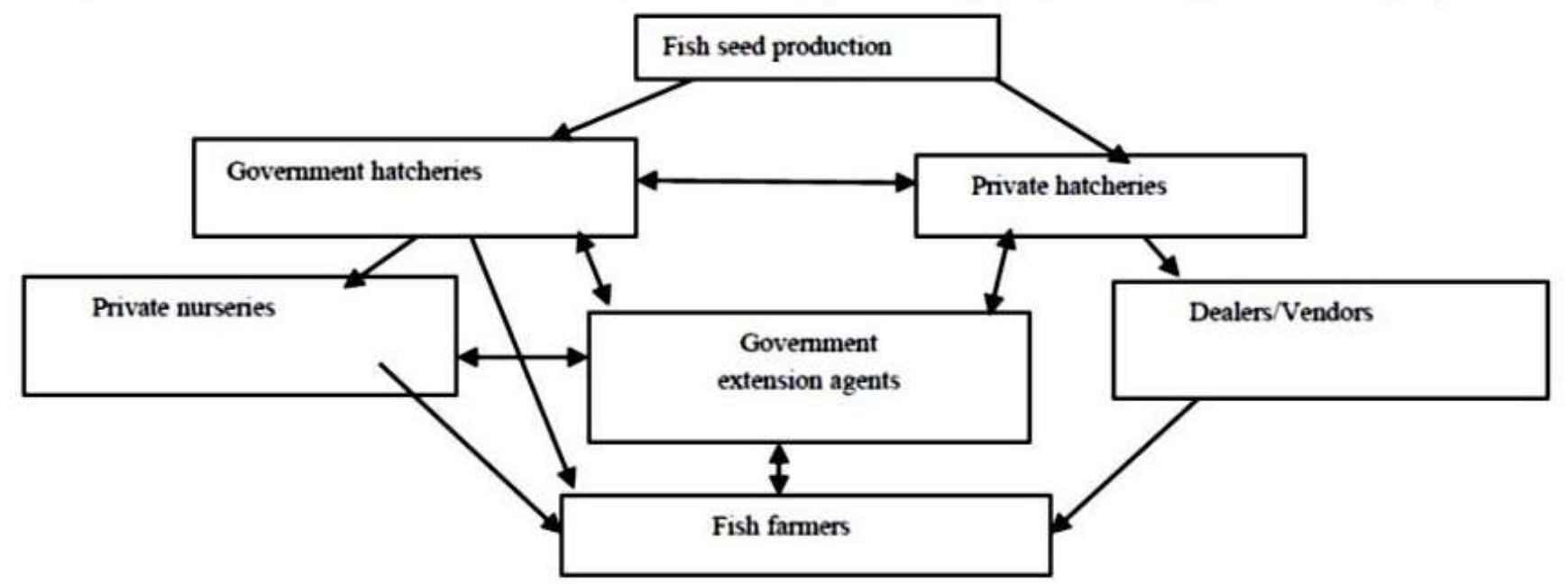

Fig. 4: Existing Carp seed production and distribution system in Nepal 
During 2013 to 2014, the different fish seed service providers had altogether distributed 1117 ANEP HH and 3249 Value Chain HH. The highest fish seed distributed to ANEP beneficiaries by Patel Hatchery was $240 \mathrm{HH}$ in 2014 and lowest goes to Pradip Fish Nursery with $14 \mathrm{HH}$ in 2014. Similarly, the highest fish seed distributed to Value Chain beneficiaries is also by Patel Hatchery with $1120 \mathrm{HH}$ in 2014 and lowest goes to Pradip Fish Nursery with $21 \mathrm{HH}$ in 2014 (Fig. 5). Besides ANEP beneficiaries, different farmers were also get free technical service with quality fish seeds developed by ANEP.

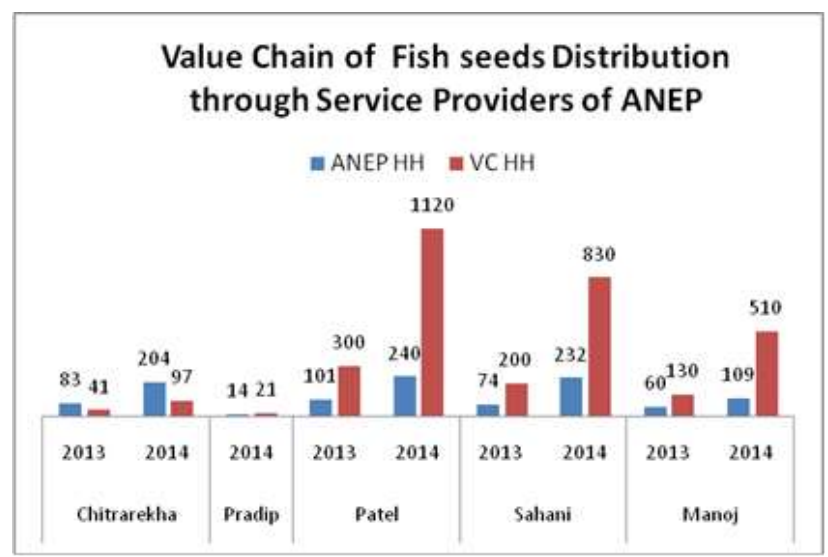

Fig. 5: Distribution of Fish seeds through Service Providers of ANEP
Moreover, it seems number of farmers are increased in aquaculture sector with the notion of fastest growing industry comparatively with other sectors. Actually, value chain modality based on PMCA developed by ANEP found quite effective in rural resource poor farmers' context where farmers and villages are scattered and access to resource in time is realized difficult for upliftment of aquaculture development (Fig 6). It is well known fact that most of the farmers in developing countries like Nepal are illiterate and they do not have well access in information. Basically, fish farmers in remote areas of Nepal are not well equipped with skills and knowledge transfer among them with better service delivery. There is gap in exchange of mutual understanding, market access, problem solving platform in a interactive way. PMCA deals effectively in due course of combining different thoughts in one place participating different ideas and solutions among the different actors of the society. It helps in motivating the farmers towards quality products, strengthen their capabilities of decision making and ensures the selection of right choice. It developed trust among farmers and actors to be a equal partner of their profession and business acceleration. This will simply ties the different motives in one direction with better output.

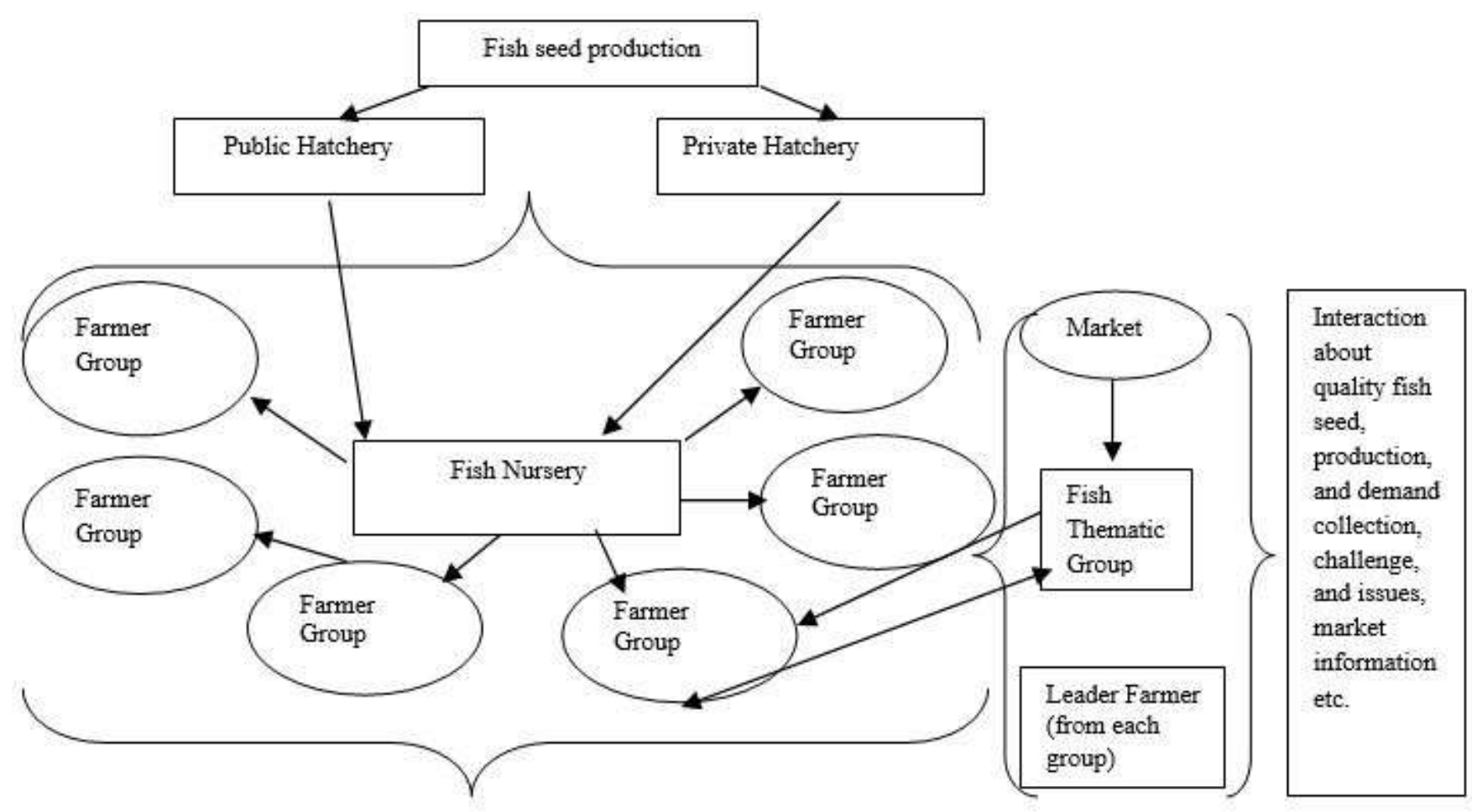

Pocket wise approach

Fig. 6: ANEP model for Fish seed dissemination process through PMCA 
In Nepal, fish seed production has been governed mainly by two sectors i.e. government based fish farm (Public sector) and private hatchery and nurseries (Private sector). According to DoFD 2011, the total fish seed production was 113739000 in which contribution of Public sector and Private sector was 22018000 and 91721000 with $19 \%$ and $81 \%$, respectively. This figure reveals that production of fish seed by private sector is four times greater than the private sector in Nepal (Table 1). In context of fish seed production, there are 14 Government hatcheries and 54 private hatcheries for carp seed production. Moreover, 11 Government and 33 private was now in operation whereas 123 fish nurseries are in operation in Nepal (Mishra, 2013). Fish seed production trend was found quite optimistic as the increased fish seed production per annum in Nepal based on the graph from 2058/2001to 2070/2013 (Fig 7).Carp contribute more than $95 \%$ in total aquaculture production in Nepal. Exotic Carps contribute nearly $70 \%$ of aquaculture production. Fish seed production trend in Nepal is improving yearly and there was a significant demand of fish seeds based on different sizes for public and private actors (Mishra, 2013).

Table 1: Fish Seed Production/Distribution (No. in '000) (DoFD, 2011/2012)

\begin{tabular}{|c|l|}
\hline Public Sector & $\mathbf{2 2 0 1 8}$ \\
\hline a. Hatchling & 122515 \\
\hline b. Fry & 15150 \\
\hline c. Fingerling & 6868 \\
\hline Private Sector & $\mathbf{9 1 7 2 1}$ \\
\hline a. Fry & 91721 \\
\hline
\end{tabular}

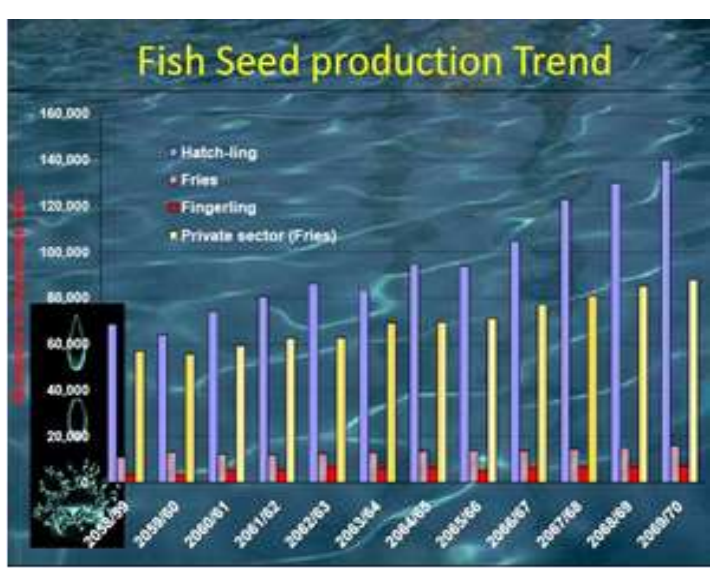

Fig.7: Fish seed production trend in Nepal (Source: Mishra, 2013).

Fish seed production and dissemination approach adopted by ANEP had been found quite holistic approach. In this approach, ANEP promoted fish nurseries and hatcheries based on pocket/cluster are established in Rupandehi and Nawalparasi district of Nepal. The fish nurseries and hatcheries promoted by ANEP in concerned pockets collected fries/fingerlings demand in thematic group meeting based on whole VDC, fish farmers' group and community. And estimated fish seed demand based on group level discussion will come out as a outline of estimated fish seeds need. Based on the fish seed demand, required amount of hatchlings were demanded from reliable government and private hatcheries by the fish nurserer. It ensured the quality of fingerlings and trust building among the farmers as they sit in a common platform i.e. fish thematic group meeting along with market actors in a participatory and organized way. Actually it was motivated through the fish thematic group meeting based on PMCA. And there is also positive empowerment in fish farmers regarding this issue in Nawalparasi district and hatchery owners have realized and started in implementation of this practice very positively. The practice of timely interaction on farmers' level problems, issues will be beneficial to identify a proper solution and technical outcome regarding different farm level issues for further improvement to the farmers (Fig. 6). Total Production of Fish Seeds by Service Providers of ANEP in both Rupandehi and Nawalparasi districts were found 106000000, 161403500 and 242197000 with $21 \%, 32 \%$ and $47 \%$ in 2012, 2013 and 2014 respectively (Fig. 8). Similarly, Total sale of fish seeds by Service Providers of ANEP in both Rupandehi and Nawalparasi districts were found 3150000, 5336375 and 9060000 with $18 \%, 30 \%$ and 52\% in 2012, 2013 and 2014 respectively (Fig. 9).

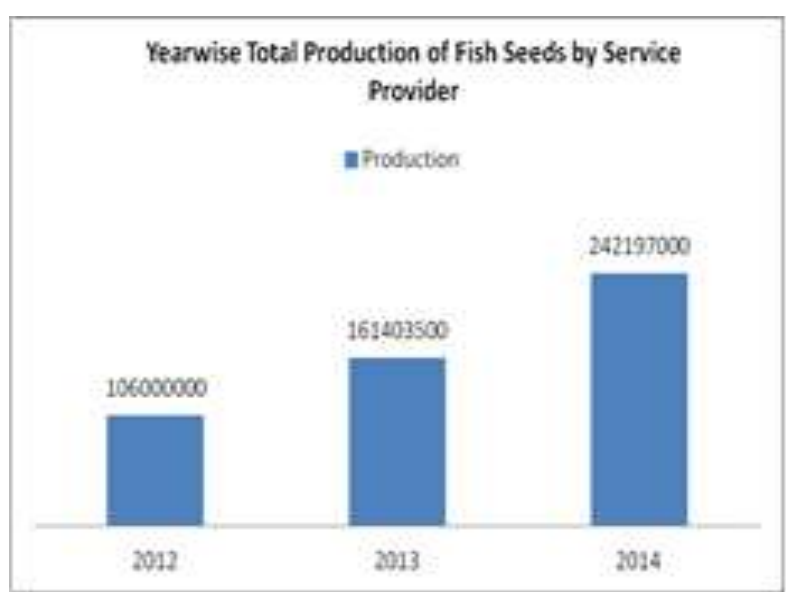

Fig. 8: Yearwise Total Production $(\mathrm{Kg})$ of Fish Seeds by Service Providers in ANEP Districts

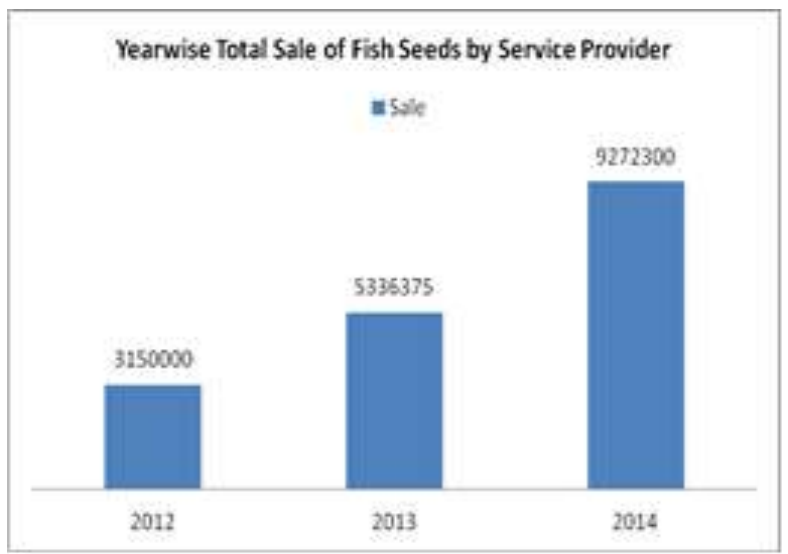

Fig. 9: Yearwise Total Sale (NRs.) of Fish Seeds by Service Providers in ANEP Districts 


\section{Acknowledgement}

The authors wish to acknowledge the support of Agriculture and Nutrition Extension Project of the European Union, CEAPRED and WorldFish. Special thanks are extended to all the project staffs, fish farmers, market actors and service providers who actively participated in different phases of this work.Last but not the least, we would like to extend our sincere thanks to Dr Murshed Khondker E-Jahan, Worldfish Center, Bangladesh for his untiring support and effort provided in ANEP.

\section{References}

ANEP (2013) Progress Report. Agriculture and Nutrition Extension Program. Nepal.

APP (1995) Agriculture Prospective Plan (APP). APROSC, Kathmandu and John Mellor Associates Inc, Washington DC.

DoFD (2011/012) Country report. Department of Fisheries Directorate. Government Nepal.

FPP (2000) Fisheries Perspective Plan (FPP). Directorate of Fisheries Development. Department of Agriculture,Ministryof Agriculture and Cooperatives, Government of Nepal, Kathmandu. (Draft version).

Humphrey J and Navas-Alemán L (2010) Value chains, donor interventions, and poverty reduction: A review of donor practice. Brighton, England: IDS Research Report 63.

Mathema BB (1992) Fisheries institutional structure: past, present and future. Proceedings of the Workshop on Human
Resource Development in Fisheries Research in Nepal. Fisheries Research Division Godawari, Nepal Agriculture Research Council, Lalitpur, pp. 6-21.

Mishra RN (2013) Carp Seed Quality Improvement Program in Nepal. Paper presented at seminar on Aquaculture in Nepal: recent development and future prospects, Kathmandu, Nepal.

MoAC (2009) National Agri Policy 2061 (in Nepali). Ministry of Agriculture and Cooperatives, Government of Nepal, Kathmandu. Retrieved 5 August 2009, from http://www.moac.gov.np/publications/index.php

NARC (2009) 20 Years Agricultural Research Vision (unofficial translation). Nepal Agriculture Research Council, Kathmandu, Nepal.

NARC (2010) NARC's Strategic Vision for Agricultural Research (2011- 2030): Meeting Nepal's Food and Nutrition Security Goals through Agricultural Science \& Technology. Nepal Agricultural Research Council (NARC), Kathmandu. Retrieved 30 December 2010, from http://www.narc.org.np/narc vision/NARC vision.pdf

Staritz C (2012) Value chains for development: Potentials and limitations of global value chain approaches in donor interventions. Austrian Research Foundation for International Development, Vienna.

Stoian D, Donovan J, Fisk J and Muldoon M (2012) Value chain development for rural poverty reduction: A reality check and a warning. Enterprise Development and Microfinance 23(1): 54-69. 